\title{
NON-OPTIONALITY AT ZULU L2 FIRST SYNTAX
}

Dr Sibusisiwe Dube

Assistant Director: Rainbow Language Services

The Valueless Features Hypothesis of Eubank $(1993 / 94 ; 1994 ; 1996)$ proposes that certain types of apparently optional syntactic processes that appear in initial and not in mature state grammars are due to a lack of specification of inflectional feature values at the initial state of grammatical knowledge. Thus the apparent optionality in the placement of medial adverbs vis-à-vis thematic or finite main verbs evident in the early stages of second language (L2) acquisition is attributed to non-transfer of the strength values of morphological features instantiated in the learners' first language (L1). This paper provides experimental evidence from Zulu $L 2$ acquisition of verb raising by English native speakers, which suggests non-optionality in the early developmental stages of L2 syntax. The paper suggests that the initial obligatoriness of a non-verb raising syntactic analysis evident in the early stages of Zulu L2 acquisition is L1-based; indicating transfer of [strong] $V$ features in $T$ instantiated in English.

Die 'Valueless Features Hypothesis' van Eubank' (1993/94; 1994; 1996) stel voor dat sekere tipes skynbare opsionele sintaktiese prosesse wat by aanvanklike grammatikas voorkom, maar nie by grammatikas in 'n gevorderde stadium nie, die gevolg is van 'n gebrek aan spesifikasie van infleksionele kenmerkwaardes tydens die aanvanklike stadium van grammatikale kennis. Derhalwe word die skynbare opsionaliteit in die plasing van tussenbywoorde teenoor tematiese of hoofwerkwoorde in 'n persoonsvorm wat by die vroeë stadiums van die aankweek van 'n tweede taal (L2) duidelik blyk, toegeskryf aan die nie-oordrag van die kragwaardes van morfologiese kenmerke wat in die leerder se eerste taal (L1) geïnstansieer is. Hierdie skripsie lewer eksperimentele bewyse van werkwoordverheffing by die aanleer van Zulu (L2) deur aangebore Engelssprekendes, wat nie-opsionaliteit in die vroeë ontwikkelingstadia van L2sinsleer suggereer. Die skripsie stel voor dat die aanvanklike verpligting van 'n niewerkwoordverheffende sintaktiese ontleding, wat in die vroeë stadium by die aanleer van Zulu L2 voorkom, L1-gebaseer is; wat dui op 'n oordrag van [- sterk] V-kenmerke in $T$ wat in Engels geïstansieer is.

\section{INTRODUCTION}

One of the recent questions concerning second language acquisition research has been the extent to which functional categories transfer from the learner's first language (L1) grammar to second language (L2) 'First Syntax' (Paradis \& Genese, 1997), i.e. the starting point of non-native grammatical knowledge. Of the theories that predict transfer of L1 functional categories to the initial L2 mental representation, one can identify two contrasting views on the extent to which L1-based functional categories form part of L2 first syntax. The Full Transfer/Full Access Hypothesis (Schwartz \& Sprouse, 1994; 1995; 
1996) proposes that the totality of the $\mathrm{L} 1$ functional structure transfers to the initial state of L2 acquisition. On the other hand, the Valueless Features Hypothesis (Eubank, 1993/94; $1994 ; 1996)$ states that transfer of L1-based functional categories is in fact limited. Eubank proposes that while functional categories transfer, morphology-driven strength of inflection does not. As a result, initial state L2 grammars are characterised by L1-based functional heads whose feature values are 'valueless' or 'inert', i.e. the feature values are unspecified. The claim is that valueless/inert features lead to apparently optional syntactic movement in early L2 development. With regard to the acquisition of verb raising, the Valueless Features Hypothesis (VFH) proposes that there is an early period in the interlanguage grammar during which INFL is underspecified for strength and thus allows optional raising of finite main verbs.

The aim of this paper is to investigate the L2 acquisition of Zulu verb raising in light of the claims of the VFH. The property related to verb raising that will be central to this investigation is adverb placement vis-à-vis the finite main verb. It has been suggested that verb raising determines the position of temporal adverbs in relation to the finite main verb (Pollock 1989). In view of the above, the question asked in the study is whether or not English-speaking beginner learners of Zulu will distinguish in acceptability between verb raising and non-verb raising sentences. If early $\mathrm{L} 2$ grammars are characterised by syntactic optionality as proposed in the VFH, then English-speaking L2 learners of Zulu are not expected to distinguish between the two sentence-types. On the other hand, if they have a significant preference for one sentence-type over another, this would be an indication of non-optionality in the early interlanguage grammar.

The paper is organised as follows. Section 1 below is an outline of the theoretical framework used and the main concepts central to the study. The section also provides syntactic background of the verb raising parameter in general and its realisation in the Zulu language. Section 2 is a review of the claims of the VFH regarding the nature of early L2 competence. The central purpose of this section will be to develop the rationale and general predictions for the experimental study. Section 3 comprises of a standard description of the experiment, the methods used, subjects and test sentences while section 4 is a report of the results of the experimental study. The final section of the paper places the results on the acquisition of Zulu verb raising on the larger picture of the claims of the VFH by paying particular attention to its proposals regarding non-transfer of L1-based feature values and the nature of the initial state L2 grammar.

\section{SYNTACTIC BACKGROUND}

\subsection{Word Order and Verb Raising: A Minimalist Perspective}

The theoretical framework that will be used in the syntactic analysis of Zulu adverb placement and verb raising is the Minimalist Program (see Chomsky, 1993, 1995a, Marantz 1995) ${ }^{1}$. The basic claim in the Minimalist Program (MP) is that the only parametric difference in the world's languages is reducible to properties of functional categories. A movement analysis is motivated on the basis that all languages are universally $\mathrm{SVO}^{2}$ and any other surface word order that departs from this universal word order is derived by movement (Kayne 1994). Movement to the functional domain is claimed to be invariably leftward, thus verb movement to the right does not exist. As a result, functional projections hosting V-features are assumed to be head initial. This 
suggests that licensing positions (i.e. specifier positions) must be on the left-hand side of the licensed category. Thus, an adverb will always be on the left of the verb, giving rise to an underlying $\mathrm{AV}$ word order.

There are principles that constrain movement, the three most important of which are (1) morphological feature checking requirement, (2) 'greed' and lastly, (3) 'procrastination'. These three principles explain why an element moves, which element has to move and when it has to move. In the MP movement must be motivated and any movement that is not triggered by a requirement of morphological feature checking is excluded. Two types of features, which are mainly operative within the I-system, are $\mathrm{N}$-and V-features ${ }^{3}$. Chomsky (1993, 1995a, 1995b) states that Agr(eement and T(ense) represent morphological features of the verb hence these are called V-features. Their derivational function is to check the $\mathrm{Agr}$ and $\mathrm{T}$ features of the verb. The question is which category moves, is it the verb or INFL(ection).

The principle of greed determines which category in the derivation moves. In the MP an inflected lexical element moves if and only if it contains overt morphology of the target of movement. To check Agr and T features the category that carries BOTH Agr and T morphology must move to check these features off. Because verbs emerge from the lexicon fully inflected, an already inflected verb is inserted into its base position in the VP. These morphological features have strength values. They are marked as strong/weak depending on the morphological paradigms of the language concerned. The inflectional nodes Agr/T do not add inflections to the bare verb, i.e. there is no lowering of inflection (Chomsky, 1995b). The function of the I-node is simply to check if the verb has the appropriate features.

The timing of movement in a derivation is determined by the principle of procrastination. Procrastination requires that movement be delayed as long as possible, i.e. until it is necessary for an element to move. Thus, procrastinate requires that all movement takes place after spell-out (i.e. covertly), but like any ranked constraint, procrastinate is violable so as to ensure convergence at the PF interface level ${ }^{5}$. In other words, derivations that would be illegitimate at PF must be eliminated in overt syntax and thus allowing movement to take place before spell-out.

In summarising, verbs move to the INFL node to check Agr and T features. Languages differ in terms of when movement occurs, i.e. either before or after spell-out. The principle of procrastinate suggests that all movement must be delayed until after spell-out but the need to check morphological features forces movement to take place before spell-out. The deciding factor on whether or not procrastinate is to be adhered to or violated is the strength of the morphological features. Weak features can appear at PF without causing the derivation to crash so procrastinate can be adhered to. Strong features are illegitimate $\mathrm{PF}$ objects and these must be checked off before spell-out thereby violating procrastinate in order to save the derivation from crashing.

\subsection{The Verb Raising Parameter}

Amongst other structural properties, verb raising determines the position of sentenceinternal adverbs in relation to the thematic main verb, i.e. whether the adverb precedes or succeeds the main verb. The assumption is that in verb raising languages the finite thematic verb moves to INFL giving rise to the Subject-Verb-Adverb-Object (SVAO) 
word order whereas in non-verb raising languages the Subject-Adverb-Verb-Object (SAVO) word order obtains. To some extent, verb raising is related to surface word order, ${ }^{6}$

Current syntactic theories hold that the notion of syntactic movement is expressed in terms of strength of inflection. In this framework, movement is obligatory and not optional (Chomsky, 1993). As already stated, movement is triggered by morphological feature checking requirements (Epstein et.al, 1996). Features whose values are [+strong] must be checked off before spell-out so that the derivation does not 'crash'. The claim is that [+strong] features require overt raising of lexical items to check off these strong features. Because [+strong] features are illegitimate PF objects, these are eliminated at overt syntax thereby violating the principle of procrastinate. Weak features, i.e. features whose value is [-strong] prohibit overt raising of lexical items. Weak features are inoffensive and can appear at PF and these adhere to the principle of procrastinate hence they are eliminated at covert syntax. The variation in feature strength leads to word order differences that are a function of either overt or covert movement.

Feature strength is determined on the basis of richness of verbal paradigms (Rohrbacher, 1994; Chomsky, 1995a). For example, in languages like French where verbal morphology is rich, the feature value for $T$ is [+strong]. Because English has a meagre verbal paradigm, inflection is assigned [-strong] as the feature value for $T$. With regard to verb raising, this difference in feature strength correlates with different types of verb movements in different languages. In French-type languages where the feature value is [+strong] the finite main verb moves overtly giving rise to the SVAO word order whereas in English the verb does not move overtly. The verb moves covertly at LF and this gives rise to the SAVO word order. Because movement is obligatory and not optional, the $\mathrm{V}$ features in $\mathrm{T}$ can either be [+strong] or [-strong] but can never instantiate both values. With regard to the placement of adverbs, this suggests that a language can either have SVAO or SAVO and not both word orders as this would be an indication of optional syntactic movement. Thus SVAO is a syntactic correlate of $[+$ strong $] V$ features in T while SAVO is a syntactic correlate of $[-$ strong] features.

\subsubsection{Verb Raising in Zulu}

Adhering to the minimalist assumptions outlined in 1.1, the underlying word order in Zulu is SVO and the adverb as a 'licensor' occupies the specifier position of the VP giving rise to an underlying word order $\mathrm{SAVO}^{7}$. Since the verb in Zulu carries both Tense and Agr greed requires that the verb must move to INFL to check these features. These give rise to the simplified version of Zulu base structure shown in Figure 1 below. 


\section{Figure 1: Zulu Base Structure}

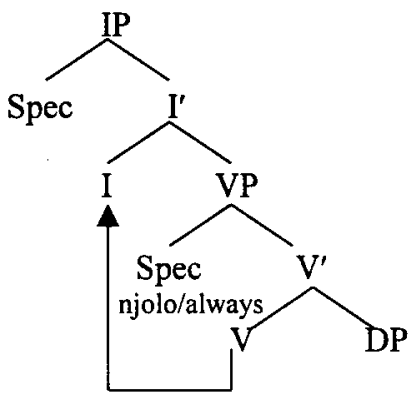

With regard to verb raising, a significant parametric difference between Zulu and English is verb raising in the former but not the latter. This syntactic difference is evident in the placement of adverbs as shown in example (1) and (2) below. ${ }^{8}$

1. Abafana ba wa shaya njalo amantombazana'.

boys $\mathrm{AgrS}^{10}$-Agr0 ${ }^{11}$-beat often girls)

( ${ }^{*}$ The boys beat often girls)

2. Uthishanhloko $\mathfrak{u}$ ba fund is a njalo abantwana be nkosi. (Teacher head AgrS-Agr0-teach-Caus-Tns oftenalways children of-king (*The headmaster teaches always/often the king's children).

In Zulu, unlike in English, sentences with the verb in situ are ungrammatical as shown in (3) and (4) below.

(3). *Abafana njalo ba shaya amantombazana. (a/the boys often AgrS-beat girls)

(The boys often beat girls

(4) *Uthishanhloko njalo $\mathrm{u}$ fund is a abantwana be nkosi. (teacher head often AgrS- teach-Caus-Tns children of-king) (The headmaster often/always teaches the king's children).

The rich agreement of Zulu verbal morphology renders the feature value for inflection [tstrong]. The lexical finite main verb raises overtly in Zulu to check off [+strong] $\mathrm{V}$ features in $\mathrm{T}$ leaving behind the adverb (e.g. 1 and 2). By allowing its verbs to move overtly before spell-out, Zulu accords with the violability of procrastinate. In contrast, English lexical verbs cannot move because of the impoverished agreement that renders the value of the $\mathrm{V}$ feature in $\mathrm{T}$ [-strong]. In English the adverb remains to the left of the in situ complement-taking verb. This explains the grammaticality of the English equivalent of sentences (3) and (4). In these examples the complement-taking verb has not been raised overtly but, rather, covertly. But covert movement has no visible effect on word order. Example (3) and (4) are ungrammatical in Zulu because [+strong] $\mathrm{V}$ features require the 
lexical verb to raise overtly so that these features are checked off before spell-out. Derivation (3) and (4) 'crash' because the strong V features have not been checked off. But the equivalent derivations do not 'crash' in English because the lexical verb does not need to move overtly for feature checking. To satisfy procrastinate the lexical verb in English only moves at covert syntax.

By and large, Zulu and English vary in the type of movements they permit. In Zulu overt raising leads to a situation whereby the temporal adverb appears between the complementtaking verb and the complement itself while covert movement in English leads to the temporal adverb appearing before the complement-taking verb. The difference in the placement of temporal adverbs in the two languages is an indication of variability in strength of inflection.

\section{CLAIMS OF THE VALUELESS FEATURES HYPOTHESIS}

The Valueless Features Hypothesis (VFH) argues against the strong view of full transfer of the L1 functional geometry. Eubank proposes that although categorical and directionality parameters of the L1 transfer, the strength values of morphological features located under functional heads do not. The unspecified features at the L2 initial state are dubbed 'valueless' or 'inert'. It is these unspecified features which lead to the appearance of optionality of syntactic movement in developing L2 grammars. The lack of specification of the feature values at the L2 initial state render the early L2 grammar 'unnatural'. This follows from the claim that features have exclusive values in that these can either be $[+]$ or $[-]$ strong but they cannot have unspecified values. In the framework used by Eubank, there is 'no possible grammar in which an element moves optionally, it must move obligatorily, or not at all' (Henry, 1997:63) ${ }^{12}$.

Eubank adopts the view that syntactic phenomena such as verb raising depend on the strength values of inflectional features (Pollock, 1989; Chomsky, 1993). The guiding principle in the VFH thesis is that overt inflectional morphology does not transfer and neither do the parametric values of features associated with this morphology. Following Rohrbacher (1994), Eubank assumes that feature strength is determined by morphological paradigms. The strength of morphological features acts as a trigger for the acquisition of the relevant syntax, i.e. when the verbal morphology of the target language (TL) has been sufficiently acquired, the strength values of the relevant features are determined and the syntactic correlate appears consistently in the developing grammar. In other words, once the verbal paradigm has been acquired, the relevant syntactic correlate (e.g. verb raising or non-verb raising) consistently reflects the exigencies of the feature value of the TL in that either obligatory movement or non-movement obtains. By assumption most advanced nonnative speakers are not expected to show any syntactic optionality as optionality is resolved once the verbal paradigm of the TL has been acquired. ${ }^{13}$

Eubank's empirical evidence for the VFH comes from the acquisition data on adverb placement of Francophone L2 learners of English reported in White (1991/92, 1991, 1992). Eubank points out that there is optional adverb-placement in the interlanguage grammar of early Francophone learners of English because they use both SAVO and SVAO word orders. Eubank states that the word order patterns shown in early FrenchEnglish interlanguage does not resemble that in the learners' L1, indicating non-transfer of $\mathrm{L} 1$ feature values. If the [+strong] $\mathrm{V}$ features in $\mathrm{T}$ instantiated in French, the subjects' $\mathrm{L}$, 
had been transferred then the syntactic correlate would have been verb raising giving rise to an obligatory SVAO word order. Because English [-strong] V features have not yet been determined and the [+strong] features of French do not transfer, the initial state interlanguage grammar has 'inert' or 'valueless' features. Eubank attributes optionality in the use SVAO and SAVO word orders to a lack of specification of the feature value of the head of the functional projection TP (or IP) dominating VP. ${ }^{14}$ In other words, INFL is underspecified for strength hence the appearance of optionality in the developing grammar. $^{15}$

The claims of the VFH can be summarised as follows: first and foremost, feature values instantiated in the native language do not transfer to the L2 initial mental representation. The acquisition of overt agreement morphology leads to the determination of the target language feature values, which then trigger the acquisition of the correlate syntax. Development in the interlanguage grammar is from optionality at the initial state to an abrupt resolution of optionality at subsequent 'intermediate/advanced' stages.

Eubank's view of interlanguage syntactic development is largely 'constructionist', ${ }^{16}$ i.e. learners construct an L2 system on the basis of target language triggering evidence only. The VFH does not, in this regard, take into consideration the role that might be played by feature values instantiated in the L1 grammar in the development of the L2 system. This view contrasts with the 'reconstructionist' view or the failure-driven approach proposed by Schwartz \& Sprouse $(1994 ; 1995 ; 1996)$. In the failure-driven approach change in the interlanguage is motivated by $\mathrm{L} 2$ input that cannot be assigned a representation by the initial state grammar (i.e. the L1 final state). In this view, subsequent restructuring in the interlanguage grammar is only envisaged if the $\mathrm{L} 1$ and $\mathrm{L} 2$ parameter-settings differ.

Schwartz (1998) points out that the VFH can be falsified if it can be shown that L1-based feature values whether strong or weak, characterise the early stages of L2 syntactic development. For instance, if obligatory non-movement or movement (short or long distance) instantiated in the $\mathrm{L1}$ is initially realised as such in the early stages of L2 development, this would be evidence of non-optionality of syntactic movement. In fact, evidence of non-optionality of movement is reported in Dube's (1997; 1998) studies where English speaking $L 2$ learners of Zulu obey subjacency in their acquisition of non-subjacent Zulu pseudo-gap topics. As the topics are base-generated in situ, subjacency does not apply in Zulu. Subjacency applies in English because topics are derived by wh-like movement which is driven by [+strong] wh-features in C. By imposing a subjacency constraint in Zulu topicalisation, the early English-speaking L2 learners of Zulu show that [+strong] wh-features instantiated in their L1 transfer to the L2 initial state grammar.

The results in Dube's studies dovetail with the findings in Green (1996). In Green's study, native speakers of the Cantonese dialect of Chinese impose their base-generated structural analysis in their acquisition of English topicalisation. The base-generation analysis used in the very early stages of development in L2 English suggests transfer of L1-based [-strong] features. In both studies, there is evidence of non-optionality of syntactic movement. In Dube's studies obligatory movement operations in the Ll grammar are realised as such at L2 first syntax while in Green it is obligatory non-movement that is used at the initial state. While the VFH proposes that feature values do not transfer to the initial L2 mental representation, the results reported in Dube $(1997$; 1998) and Green (1996) reveal that L1based feature values also transfer to the initial stages of L2 syntactic development. The 
results in both studies cast doubt on the claims of the VFH regarding non-transfer of L1based feature values.

\subsection{Hypotheses and Predictions}

The aim of this study is to establish the nature of the initial state grammar with respect to the extent to which the L1 functional geometry transfers, i.e. whether or not functional categories together with their feature values transfer to the initial state of L2 syntax. Assuming the proposals of the VFH outlined above, the primary research question is; will native speakers of English learning Zulu as a second language initially assume that Zulu is like English with respect to the feature value of T? More specifically, will they initially prefer non-verb raising to verb raising sentences? The VFH predicts that English speaking L2 learners of Zulu will not distinguish in acceptability between grammatical verb raising and ungrammatical non-verb raising sentences, thus allowing syntactic optionality in their early grammar.

The null hypothesis for the present. study is that the initial state L2 grammar is characterised by a full conservation of the $\mathrm{Ll}$ functional geometry. With regard to the acquisition of adverb placement in Zulu, it is predicted that English L2 learners of Zulu will transfer their [-strong] $\mathrm{V}$ features in $\mathrm{T}$ hence beginner learners will distinguish in acceptability between grammatical verb raising and ungrammatical non-verb raising sentences by significantly preferring ungrammatical non-verb raising sentences. In other words, non-optionality of syntactic movement is predicted at the Zulu L2 initial state.

\section{THE EXPERIMENTAL STUDY}

\subsection{Subjects}

The experimental study consisted of 151 native speakers of English learning Zulu, at various stages of proficiency as well as subjects who were working in Zulu-oriented jobs! There were also 38 native speakers who served as controls. ${ }^{17}$ The 151 learners included students studying and teachers teaching Zulu at primary and high schools in the Johannesburg and Pietermaritzburg area. There were also trainee teachers, university and college lecturers and professors in Zulu departments. The experimental group also included those who were native speakers of English working in Zulu-related jobs such as TV personnel, including TV newsreaders, journalists and senior editors. The 38 native controls were students of Law and Engineering at the universities of the Witwatersrand and Natal.

L2 proficiency was determined on the basis of scores on a cloze test, which was administered to all subjects, including the native controls. The reason for using the cloze as an independent test was that there was a lot of variation amongst the subjects in terms of the quality and quantity of input they were exposed to, such that the criterion of years or months of exposure to the TL would not have been useful. Some of the subjects had lived in a Zulu-speaking environment, while others had private tutors; some had been taught by native speakers while others had always been taught by non-native speakers, thus suggesting that the quality and quantity of input the participants had been exposed to differed greatly. 
Based on the scores of the cloze test, the subjects were then divided into five proficiency levels; excluding the native control group. The experimental subjects were grouped as follows: group one (nns1) constitutes the most elementary group or the beginner learners. Most of the subjects in this group had been on a Zulu language course for a period of three months. Group two (nns2) is the low intermediate group while group three (nns3) is the high intermediates. Group four (nns4) consists of advanced learners while group five (nns5) consists of the most advanced L2 learners of Zulu, i.e. the near-native group. Most of the subjects in this group had studied Zulu for over twenty-five years. Group six was the native control group (Ns).

\subsection{Sentences Used}

In conducting the entire study, three types of sentences were used, namely; pre-test, fillers and test sentences. The purpose of each one of the sentence-types is described below.

\subsubsection{Pre-test Sentences}

The pre-test sentences were used for training before the actual experiment took place. The sentences consisted of difficult as well as simple sentences. The pre-test sentences were constructed along the same lines as the main experimental sentences. The only difference between the pre-test and the test sentences is that whatever syntactic feature is varied, it is not part of the investigation. This was meant to familiarise the subjects with the task, especially the use of numerical magnitude estimation, which is a fairly new method of assessing linguistic intuitions.

\subsubsection{Fillers}

The filler sentences were used in order to mask the regularities that could be detected in the test sentences. They had the same structure and similar lexical content as the actual test sentences. In ordering the test sentences, fillers were interposed between sentences and each filler sentence was inserted after each test sentence. This was meant to break the sequence of similar test materials.

\subsubsection{Test Sentences}

The only construction related to verb movement that is represented in the design is adverb placement. Eight sentences were constructed, corresponding to two variants of the basic construction. The syntactic variants were constructed by varying a single binary-valued syntactic feature, i.e. [+/-strong] V. Thus in all the test sentences, the syntactic features are: (1) presence of movement (+strong V) giving rise to a grammatical sentence (see examples 1 and 2) and, (2) absence of movement (-strong V) giving rise to an ungrammatical sentence in Zulu (see examples 3 and 4).

Standard experimental control techniques suggested in Schütze (1996) and Cowart (1997), such as random sampling of stimulus materials and counterbalancing for order effects (Derwing, 1979) were followed. The order of the stimulus sentences was randomised. The sentences were randomised so that two consecutive sentences testing the same syntactic structure did not succeed each other. However, as Kaplan (1993) states, with acceptability judgement tasks, randomising is often less effective as in the course of randomising sentences which are variants of the same construction (e.g. grammatical vs. an 
ungrammatical pair) might end up next to each other. In order to avoid such problems arising, after randomising the test sentences were then interposed using filler sentences and thus creating a pseudo-random order.

The sentences were constructed in pairs so that each item has an equivalent that differs from it only in the syntactic structure under investigation. The assumption in this kind of design is that if a subject rejects or disprefers one member of a pair and accepts the other one, it can be assumed that the rejection is due to the syntax. Four lexical versions of the test materials were presented in the design. Thus, the design was a repeated measures design. This type of design was chosen in order to determine whether the response pattern is consistent and not random (see Jakubowicz, 1998). The sentences were controlled for length; sentence length ranged from 5-6 words.

In order to control for vocabulary difficulty, vocabulary booklets which contained all the vocabulary items that were to be used in the experimental sentences were provided to teachers/lecturers and all potential participants four months prior to the commencement of the research. As a result, even the elementary learners, most of whom had been on a Zulu language course for a period of three months had already had access to the vocabulary items that were used in the test sentences. ${ }^{18}$ However, subjects were not allowed to consult the vocabulary booklet during the experiment.

\subsection{Methods}

The elicitation technique used was timed judgements of acceptability. A study of acceptability judgements of English L2 learners of Zulu was conducted using the method of timed numerical magnitude estimation (Bard et. al. 1996; Cowart, 1997). The acceptability judgement test was designed to test, among other things, the acquisition of adverb placement in Zulu ${ }^{19}$ by native speakers of English. Each subject provided a judgement of the acceptability of each sentence in the form of a numerical magnitude estimate. In order to do so, subjects are asked to form or construct a continuum of acceptability by assigning any number of their choice to the first sentence (called the modulus) they see on a screen while listening to the same sentence being played on tape. Subjects are then asked to assign successive numbers to the sentences they read on screen and hear on tape proportionally to the number assigned to the first sentence presented to them as the modulus. ${ }^{21}$ There was a 10 -second interval before the next sentence was heard. The time interval had been determined on the basis of the observations made during the piloting phase of the study. It had been established during piloting that 10 seconds in between sentences was a reasonable time for both beginners and the most advanced learners.

The rationale in using a numerical magnitude estimation procedure in the present study was that: (1) being a timed procedure, it elicits immediate judgements and does not give subjects time to access their metalinguistic knowledge of the relevant structures, (2) it makes it possible to capture degrees of indeterminacy in the learner's judgements and lastly (3) it gives greater certainty (than an ordinal scale) of obtaining the subjects' subjective impressions of sentence acceptability. 


\subsection{Analysing Data}

For each pair of sentences involved in a contrast, the ratio of the numbers assigned to the two sentences provides an index of the subjects' preference. As the contrast is between a grammatical and an ungrammatical sentence, the convention adopted was that the numerator in the preference ratio is the number ascribed to the ungrammatical sentence. These ratios are expressed in the form of differences between the logs of the raw numerical magnitude estimates. In the present study, this quantity is referred to as the preference score. If the preference score is positive, the preference is for the grammatical sentence, and if it is negative, the preference score is for the ungrammatical sentence.

\section{RESULTS}

\subsection{Data from the Cloze Test}

Figure 2 below shows that the mean cloze score increases significantly from one level to the next for all adjacent levels. One way ANOVA with the scores in the cloze test as a dependent variable shows that the mean scores of the six groups differ statistical highly significantly $(\mathrm{F}=1682.9196, \mathrm{p}<0.0001)$. In post hoc Tukey tests, results of the pair-wise comparison of means show that all the six groups differ significantly and thus suggesting that the six groups were drawn from six different proficiency populations.

Figure 2: Group Means of the Cloze Test (\%)

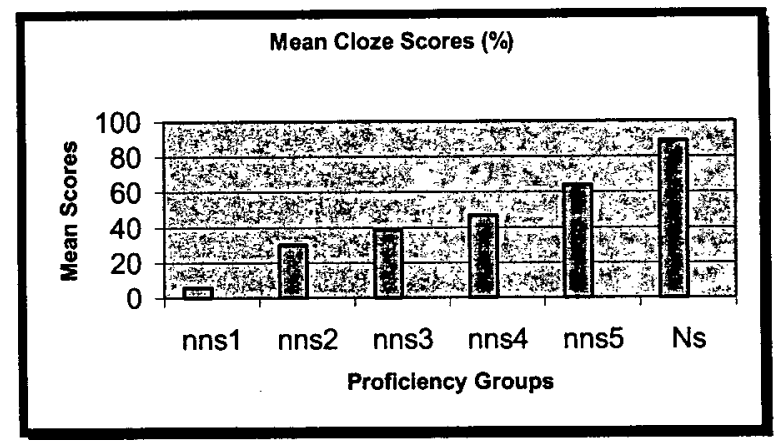

\subsection{Timed Acceptability Judgement Data}

Figure 3 below shows the mean scores of the judgements by the six groups. Recall that sentences with a raised verb are grammatical in Zulu while the equivalent sentences are ungrammatical in English. The equivalent non-verb-raising sentence is grammatical in English and ungrammatical in Zulu. 
Figure 3: Mean Preference Scores For V-Raising

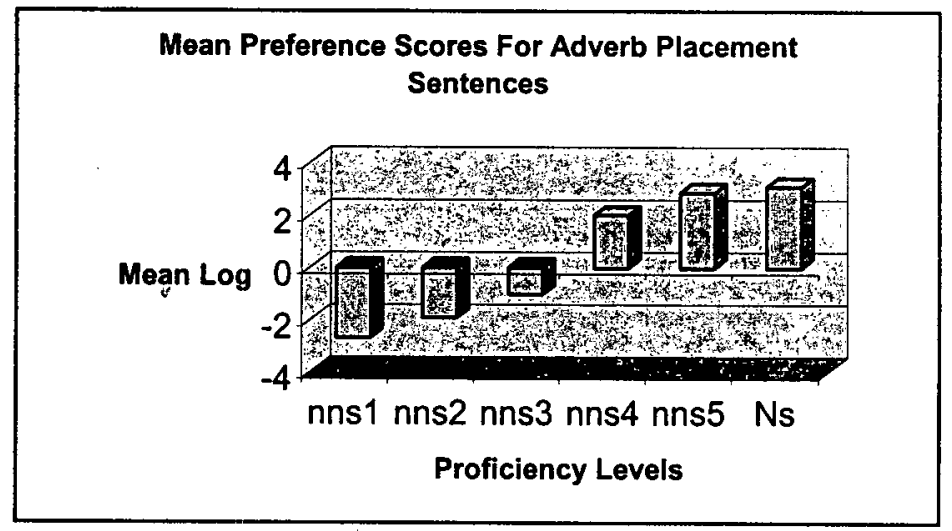

Figure 3 shows that the beginner and low intermediate groups have a preference for the ungrammatical non-verb raising sentence. The high intermediate group does not distinguish between the two sentence types whereas the advanced and near-natives have a preference for the target-like verb raising sentence just like the native speakers. The difference between the proficiency levels in the overall mean acceptability of sentences is confirmed in the main effect for level of language development in the ANOVA test $\left(F_{(5,183)}=2.70, p<0.022\right)$. Tukey tests (tabled at $\mathrm{q}=4.03$ ) show that the difference is due to the judgements of the low intermediate group in comparison to the beginner and near-native groups $(\mathrm{P}<0.05)$. The native speaker group differs only from the least advanced learners $(p<0.05)$. The main effect of raising is also significant $\left.F_{(5,183)}=9.34, p<0.003\right)$. The interaction between the effects of level of language development and verb raising is statistically highly significant $\left(F_{(1,5)}=9.84\right.$, $\mathbf{p}<0.0001$ ). In post hoc Tukey tests, within group comparison of means indicate that the first non-native groups have a statistical significant preference for the ungrammatical non-verbraising sentence $(p<0.05)$.

To summarise, the results show that in judgements of the acceptability of sentences with raised verbs, native speakers of English learning Zulu consistently express a significant preference for sentences with non-verb raising over sentences with verb raising. This preference persists until a fairly advanced stage after which it is reversed. Very advanced learners and native speakers of Zulu show a clear preference for the grammatical verb raising sentences.

\section{DISCUSSION}

The main purpose of this experimental study has been to determine the nature of the initial state grammar with respect to a still controversial topic regarding the extent to which functional categories instantiated in the learners' native language transfer to the initial stages of L2 syntactic development. The main research question revolved around the issue of whether or not initial state L2 systems are characterised by optional syntactic movement due to a lack of specification of feature values as proposed by the VFH. As indicated, the VFH argues against transfer of L1-based feature values and predicts an initial state grammar characterised by L1-like functional categories in (all) areas of grammar excluding those that imply feature strength. Regarding syntactic phenomena that implicate feature values, the VFH predicts that initial state L2 systems realise both options (i.e. $[+]$ and $[-]$ strong) before 
stabilising at the correct feature value. Consequently, syntactic movement will be optional during a period when strength of inflection is 'valueless' or underspecified. With regard to the acquisition of Zulu adverb placement, the VFH would predict that English-speaking L2 learners of Zulu will not distinguish in acceptability between grammatical verb and ungrammatical non-verb raising sentences at the very early stages of L2 acquisition.

None of the experimental subjects were at the ab initio stage of L2 acquisition. It is most common for researchers in this area to extrapolate backwards and posit an initial state grammar to be represented by some hypothetical stage 0 (see Schwartz \& Sprouse, 1996; White, 1996). In the present study the beginner group represents the initial state grammar. This is based on the observation that most of the learners in this group had been exposed to Zulu, in a formal classroom situation, for a period no longer than three months. It is therefore reasonable to assume this is as initial a state one could ever get. The assumption is that if $\mathrm{Ll}$ effects are found at this 'later' stage of development, it is plausible to assume that the L1 could have been the starting point. So what do the results on Zulu L2 adverb placement suggest?

The data presented here offer an explicit characterisation of the nature of the initial state grammar. The results show that in judgements of the acceptability of adverb placement sentences in Zulu, English-speaking L2 learners of Zulu have a significant preference for ungrammatical sentences without verb raising until a fairly advanced stage, after which this preference is reversed. In fact, beginner learners have determinate judgements. They strongly accept non-verb-raising sentences. This significant preference for non-verb raising sentences persists until high intermediate level. The conclusion that can be drawn from this observation is that low level learners distinguish in acceptability between verb and non-verb raising sentences. Thus, contrary to the claims of the VFH, the Zulu initial state interlanguage data shows evidence of non-optionality of syntactic movement.

Crucially, there is no evidence of valueless/inert or underspecified features at the Zulu L2 initial state. Since the syntactic correlate of [-strong] $\mathrm{V}$ features is non-verb raising, by significantly preferring non-verb raising sentences, low level learners evidence a grammar whose $\mathrm{V}$ features in $\mathrm{T}$ have the value [-strong]. Incidentally, [-strong] $\mathrm{V}$ features in $\mathrm{T}$ are instantiated in their L1. This indicates that, at the starting point of non-native syntactic knowledge, abstract morphological features are specified and the specification of these features resembles those in the learners' native language. This outcome suggests that strength values of inflectional features transfer from the $\mathrm{L} 1$ final state to the initial representation of interlanguage.

The initial state Zulu interlanguage grammar shows that the influence of prior language knowledge is 'absolute' (Schwartz \& Sprouse, 1995; 1996) and not limited to certain sub-parts of the L1 grammar as suggested in the VFH and Minimal Trees Hypothesis (Vainikka \& Young Scholten, 1994; 1996a; 1996b). In this respect, the Zulu interlanguage data provide evidence that L1 knowledge of morphological and syntactic form carries over into L2 acquisition. As suggested in Schwartz \& Sprouse (1994; 1996), early L2 syntactic development exhibits full transfer of L1 syntactic properties.

The account of the nature of the initial state grammar described above is based on the $a$ priori assumption that the starting point of non-native grammatical knowledge is the L1 final state. If this account is correct, it gives us an insight into the process of interlanguage grammar construction. In the VFH, interlanguage development is viewed as a process of 'construction' in those areas of grammar affected by inflectional feature values. This view of interlanguage 
development is in sharp contrast with a 'reconstructionist' view where initial interlanguage representations are determined by the nature of $\mathrm{L} 1$ parameter-settings, and subsequent stages in the interlanguage development are characterised by changes in the parameter settings as a result of triggering evidence in the L2 (see Schwartz \& Sprouse, 1994; 1996). The Zulu data reported here suggests that subsequent interlanguage development is, in fact, a process of reconstruction of the initial L1-like grammar with change to the L2 parameter-defining values occurring in later stages of development. The fact that advanced learners and near-natives have similar preferences as the native control group suggests that interlanguage grammar at ultimate attainment converges with the target language ${ }^{22}$. At least with respect to the acquisition of verb raising, the type of competence in evidence at ultimate attainment is 'complete' (cf. Sorace, 1993). ${ }^{23}$

In conclusion, the results of the experimental study suggest that morphological feature values instantiated in the learners' native language are as much subject to transfer effects as any other property of the $\mathrm{Ll}$ grammar. Considering the significant preference of non-verb raising sentences by low level learners, we cannot deny that, contrary to the claims of the VFH, the initial obligatory nature of non-verb raising shown in the early stages of Zulu L2 syntactic development provides evidence that the totality of the $\mathrm{Ll}$ functional geometry characterises the initial state of Zulu L2 syntax. Finally and most crucially, the initial obligatoriness of the non-verb raising syntactic analysis provides evidence of non-optionality of syntactic movement at Zulu L2 first syntax. On the basis of reasonable assumptions, the findings of this study suggest that L2 acquisition does not take place in vacuo. Instead, the totality of the $L 1$ functional architecture has an influence at L2 first syntax.

\section{ENDNOTES}

${ }^{1}$ The choice of the theoretical framework is based on the assumption that the VFH can best be falsified or defended by using the same theoretical assumptions that form the basis of its claims.

${ }^{2}$ Interestingly, it has been independently established that Zulu is underlyingly an SVO language and that the other remaining five Greenbergian word order possibilities evident in the language are derived by movement (Demuth 1992, Suzman 1992).

${ }^{3} \mathrm{~N}$-features check features of XPs or maximal projections while V-features are relevant for checking features of heads. Note that the $\mathrm{C}$-system has a different set of features, i.e. movement within the $\mathrm{C}$-system is triggered by operator features such as wh-, Top(ic) and Foc(us) features. Operator features do not need to be visible on the target of movement operations.

4 Cook \& Newson (1996) claim that Agr and T features universally appear on the verb. The claim for universality for these features is based on the observation that verbs and nouns are the only substantives that are found in all languages (O'Grady, 1997). However, Ratwatte (1995) provides empirical evidence to the effect that in Sinhala it is the adverb that carries both Agr and T morphology. In fact, the verb in Sinhala appears at surface syntax in its 'bare form', i.e. without any overt tense or agreement marking. Interestingly, in Sinhala it is the adverb that moves to the INFL node and not the verb. This is expected in the MP as a result of the principle of Greed.

${ }^{5}$ This view is consonant with OT in phonology where ranked constraints are violable. This similarity between OT and MP is expected considering the fact that both theories are committed to the scientific method of 'explanation through minimisation'.

${ }^{6}$ Note that Dube (1998) is very critical of the use of word order cues as an indication of whether or not verb movement has taken place. Dube reckons that a thematic verb appearing to the left of a temporal adverb is not always an indication of verb movement. For example, Kayne (1994) suggests that movement in the functional domain is invariably leftward. If Kayne's analysis is correct, then a verb appearing to the left of a temporal adverb could almost always be interpreted as an instance of verb movement. Thus instances of 'heavy NP shift' could erroneously be regarded as instances of verb movement, e.g. 'She buys usually those kinds of skirts with big belts and long, narrow slits', where the verb appears to the left of the temporal adverb usually and yet ho verb movement has taken place. Dube suggests that it would be much better to refer to an adverb being between 
a complement-taking verb and the complement itself. However, the sentences that were used in the present experiment had been carefully selected in that these were clear-cut cases of verb raising within minimalism.

7 on anonymous reviewer balked at the claim that at underlying structure Zulu has a SAVO word order. The reviewer claimed that a lot of descriptive and theoretical studies on Zulu and related African languages provide extensive data in support of SVOA word order. The reviewer gave the following sentences as examples of the underlying word order in Zulu; (1) Abafana bashaya amantombazana njalo (The boys often beat the boys, (2). Abafana bashaya amantombazana ntambama/ngalesosikhathi (The boys beat the girls in the afternoon/at that time), (3) Abafana bashaya amantombazana kakhulukaningikathathu (The boys beat the girls a lot/many times/three times) and (4)Abafana bashaya amantombazana endlini/kude lomuzi/ekupheleni kemithi (The boys beat the girls in the houselfar from home/at the end of the trees). In the MP example (2) and (4) are not part of the adverbial system. However, it seems that there is a serious problem related to the interpretation of what constitutes underlying structure within the Chomskyan school of thought. Descriptive studies would not show. anything about underlying structure. These provide a myriad of language-specific and construction specific postulates on the basis of surface language data. The aim in generative grammar is to explain how one arrives at the observable surface language data, that is to say, the starting point in generative grammar is the human computation system and how it computes language phenomena in order to arrive at surface constructions. The underlying structure is, therefore, posited on the basis of theoretical constructs not on raw language data. For example, the underlying structure of English VP shells is NPVPP (i.e. the plates put on the table) and yet at surface syntax we have VNPPP (put the plates on the table). It is therefore a coincidence that English has SAVO word order at surface syntax. In fact, this explains why covert movement has to be posited in order to explain the similarity between underlying structure and overt syntax. In any case, if Zulu had both SAVO and SVAO at surface syntax, this would suggest that the $\mathrm{V}$-features in $\mathrm{T}$ are both $[+]$ and $[-]$ strong, which in a minimalist account would be unnatural.

${ }^{8}$ The same phenomenon applies in quantifier float and Neg. placement.

${ }^{9}$ One anonymous reviewer observed that in Zulu there are sentences like those given in note 7, especially (1) and (2) which render our analysis of Zulu verb raising rather suspect. Sentences like those given by the reviewer do not cause any problems for the experimental study because these are instances of derivational optionality, which, although limited in natural languages, exists (cf. Poole 1996). How these sentences are derived is beyond the scope of this work. Such sentences would be crucial if the aim of the study was to establish the exact nature of the interlanguage grammar at ultimate attainment. The reader is referred to the articles on optionality in the special issue of the Second Language Research Journal, 16/1, 2000, especially the introduction by Sorace.

${ }^{10}$ The following abbreviations will be used; AgrS-- subject-verb-agreement, Agr0-- object agreement, Caus-causative, Tns-- tense.

"In Zulu Agr0 is not an obligatory constituent of the inflected verb stem. It only becomes obligatory if the object is not in its position adjacent to the verb (cf. Demuth \& Harford, 1999).

${ }^{12}$ Note that while optionality is discouraged in the MP, Pettiward (1997) accommodates it within minimalism by arguing that optionality derives from the timing of movement during a derivation. In other words, instances of genuine syntactic optionality (i.e. derivational optionality) are allowed in stable state grammars. But derivational optionality is different from 'apparent optionality' referred to in Eubank. Apparent optionality is unnatural in that one of the alternative representations is an illegitimate PF object in the target language. For instance, in the Zulu adverb placement sentences, SAVO is an illegitimate PF object and therefore, cannot be of equal grammatical status with SVAO or for that matter, SVOA.

${ }^{13}$ However, Sorace (1996a) provides evidence that optionality may not be resolvable in interlanguage grammars. ${ }^{14}$ Schwartz \& Sprouse (1996) suggest that the learners in these studies were not 'true' beginners. They claim that apparent optionality evident in their grammar is due to grammar competition in that the L1 grammar used at the initial state is now in competition with the newly acquired target language form.

${ }^{15}$ Schwartz (1998) is very critical of this view. She argues that if feature values are indeed 'inert' or 'valueless', it is not clear why this would necessarily lead to syntactic optionality and not 'no movement' at all.

${ }^{16}$ This only applies to those areas of grammar that require feature strength.

${ }^{12}$ Some researchers object to the use of native speaker controls (e.g. Sorace, 1996b). The reason behind this objection is that by including a native speaker control group one is not treating the interlanguage grammar as an independent system but rather as a system parasitic to the TL and thus committing Bley-Vroman's (1983) 'comparative fallacy'. In this study a native speaker control group was included on the basis that 'being a native speaker does not confer one with papal infallibility on one's intuitive judgements' (McRae cit. in Paikeday, 1985) as has been shown by subjacency studies. Subjacency studies have shown that even native speakers reject grammatical sentences $10 \%$ to $27 \%$ inaccurately. In this regard, the inclusion of a native speaker control group was essential so as to see how native speakers who supposedly know the language judge the same sentences presented to the experimental subjects.

${ }^{18}$ In most cases the words had been displayed on the walls of the language laboratory and the teacher would read them aloud together with their English meanings during the pronunciation and conversational classes. 


\begin{abstract}
${ }^{19}$ This was in the context of the verb raising parameter. Not all forms of adverb placement in Zulu fall under the cluster of properties related to verb movement. The reader is refereed to Lightfoot \& Hornstein (1994) for a detailed explication of adverb placement and verb movement.

${ }^{20}$ See Cook (1993) for the importance of providing both a visual and auditory stimuli.

${ }^{21}$ For example, if the second sentence was more acceptable (by a certain degree) a higher number (reflecting that degree) than that assigned to the first sentence should be assigned to the second, if it were less acceptable (by a certain degree), a lower number (reflecting that degree) should be assigned.

${ }^{22}$ It is important to bear in mind just how salient the mismatch is between the surface syntax of English and Zulu. Every single Zulu utterance consisting of a finite main verb will be incompatible with the initial state grammatical system transferred from English. The inability to assign a representation to such sentences will necessarily lead to restructuring of that system. Because the phenomenon being acquired is related to word order, the restructuring process is rapid which might explain the convergent competence shown at ultimate attainment (cf. Schwartz \& Sprouse 1996).

${ }^{23}$ Note that this is not to suggest that L2 competence is almost always complete at ultimate attainment.
\end{abstract}

\title{
REFERENCES
}

BARD, EG, D ROBERTSON AND A SORACE. 1996. Magnitude estimation of linguistic acceptability. Language, 72 (1): 32-68.

BLEY-VROMAN, R. 1983. The comparative fallacy in interlanguage studies: the case of systematicity. Language Learning, 33: 1-17.

CHOMSKY, N. 1993. A minimalist program for linguistic theory. In Hale, K. \& Keyser, J. (eds), A View from Building 20. MIT press, Cambridge: Massachusetts.

CHOMSKY, N. 1995a. The minimalist program. Cambridge. MA: MIT Press.

CHOMSKY, N. 1995b. Bare phrase structure. In Webelhuth, G. (ed), Government and binding theory and the minimalist programme. Oxford: Blackwell. 383-440.

CHOMSKY, N. AND H LASNIK. 1993. Principles and parameters theory. In Jacobs, J.; W Sternefeld and T Vennemann (eds), Syntax: An international handbook of contemporary research. Berlin: de Gruyter. 506-69.

COOK, V. 1993. Linguistics and second language acquisition. London. Macmillan Press.

COOK, VJ. AND M NEWSON. 1996. Chomsky's universal grammar: An introduction. Oxford: Basil Blackwell Publishers.

COWART, W. 1997. Experimental syntax: Applying objective methods to sentence judgements. Sage Publications.

DEMUTH, K. 1992. Accessing functional categories in SeSotho: Interactions at morphosyntax interface. In Meisel, J. (ed) The acquisition of verb placement, functional categories and V2 phenomena in language acquisition. Dordrecht: Kluwer Academic Publishers.

DEMUTH, K \& C HARFORD. 1999. Verb raising and subject inversion in Bantu relatives. Journal of African Languages and Linguistics, 20: 41-61. 
DERWING, BL. 1973. Transformational grammar as a theory of language acquisition: A study in the empirical, conceptual and methodological foundations of contemporary linguistics. Cambridge: CUP.

DUBE, S. 1997. Subjacency in non-subjacent Environments: The Acquisition of Basegenerated Topics in Zulu by Native English Speakers. Paper Presented at ACAL28 Conference, Cornell University, Ithaca. New York, July 11-13. 1997.

DUBE, S. 1998. The initial state of Zulu L2 syntax: A study of the emergence of a CP projection in the Zulu grammar of native english speakers. Unpublished $\mathrm{PhD}$ thesis, University of Edinburgh.

EPSTEIN, S, H THRAINSSON AND CJ-W ZWART. 1996. Introduction. In Abraham, W., S Epstein,. H. Thrainsson and CJ-W. Zwart (eds) Minimal Ideas: Syntactic studies in the minimalist framework. Amsterdam: John Benjamins.

EUBANK, L. 1993/94. On transfer of parametric values in L2 development. Language Acquisition 3: 183-208.

EUBANK, L. 1994. Optionality and the initial state in L2 development. In Hoekstra, T and BD Schwartz. (eds). Language acquisition studies in Generative Grammar. Amsterdam: John Benjamins. 369-88.

EUBANK, L. 1996. Negation in early German-English interlanguage: More valueless features in the L2 initial state. In Schwartz, BD. and L Eubank. Second language research: Special issue on the $\mathrm{L} 2$ initial state. (ed). 73-106.

FUKUI, N. 1993. Parameters and optionality. Linguistic Inquiry, Vol. 24. (3): 399-420.

GREEN, CF 1996. The origins of topic prominence in Chinese-English interlanguage. IRAL 34 (2): 119-134.

HENRY, A. 1997. Dialect variation, optionality and the learnability guarantee. In Sorace, A, $\mathrm{C}$ Heycock. and R Shilcock (eds). Proceedings of the GALA '97 Conference on Language Acquisition. University of Edinburgh: 62-67.

JAKUBOWICZ, C. 1998. Cross-linguistic Investigation. In MacDaniel, D C McKee and HS Cairns. (eds). Methods for assessing children's syntax. Cambridge: MIT press. 257285.

KAPLAN, TI. 1993. The second language acquisition of functional categories: complementiser phrases in English and Japanese. Ithaca: Cornell University: DMLL Publications.

KAYNE, R. 1994. The antisymmetry of syntax. Cambridge. MIT Press.

LIGHTFOOT, D AND N HORNSTEIN (eds). 1994. Verb movement. Cambridge: CUP.

MARANTZ, A. 1995. The minimalist programme. In Webelhuth, G. (ed) Government and Binding Theory and the Minimalist Programme. Oxford: Blackwell. 351-84. 
O'GRADY, W. 1997. Syntax: The analysis of sentence structure. In O'Grady W, M Dobrovolsky and D F Katamba (eds), Contemporary linguistics: An introduction. 181244.

PAIKEDAY, TM. 1985. The native speaker is dead! Toronto: Paikeday Publishing.

PARADIS, J. AND F GENESE. 1997. On continuity and the emergence of functional categories in bilingual first language acquisition. Language Acquisition, 6: 91-124.

PETTIWARD, A. 1997. Movement and optionality in syntax. PhD. Department of Linguistics, University of London.

POLLOCK, J-Y. 1989. Verb movement, universal grammar and the structure of IP. Linguistic Inquiry, 20: 365-424.

POOLE, G. 1996. Optional movement in the minimalist program. In Abraham, W, S. Epstein,. H. Thrainsson and CJ-W. Zwart (eds) Minimal ideas: Syntactic studies in the minimalist framework. Amsterdam: John Benjamins. 199-216.

RATWATTE, H. 1995. Activating vs. resetting functional categories: A study of the acquisition of tense and Agr by Sinhalese L2 Learners of English. Unpublished PhD Thesis, University of Edinburgh.

ROHRBACHER, B. 1994. Pronoun case over extensions and full paradigms: A theory of Vto-I raising. PhD Dissertation, University of Massachusetts, Amherst.

SCHUTZE, CT. 1996. The Empirical base of Linguistics: Grammaticality judgements and linguistic methodology. Chicago: The University of Chicago Press.

SCHWARTZ, BD. 1998. The second language instinct. Lingua, 106: 133-160.

SCHWARTZ, BD. AND R SPROUSE. 1994. Word order and nominative case: A longitudinal study of (L1 Turkish) German interlanguage. In Hoekstra, T \& BD Schwartz. (eds). Language acquisition studies in generative grammar. Papers in Honour of Kenneth Wexler from 1991 GLOW Workshops. Philadelphia, PA. John Benjamins: 317-68.

SCHWARTZ, BD AND R SPROUSE. 1995. L2 cognitive states and absolute L1 influence. Unpublished Manuscript, Durham/Indiana University.

SCHWARTZ, BD AND R SPROUSE. 1996. L2 cognitive states and the full transfer/full access model. Second Language Research, 12 (1): 73-106.

SORACE, A. 1993. Incomplete and divergent representation of accusativity in non-native grammars of Italian. Second Language Research. 9: 22-48

SORACE, A. 1996a. Permanent Optionality as divergence in non-native grammars. Paper - Presented at the $6^{\text {th }}$ Annual Conference of the European Second Language Association. EUROSLA, University of Nijmegen, 1 June 1996. 
SORACE, A. 1996b. The use of acceptability judgements in second language acquisition research. In Ritchie, $\mathrm{W}$ and $\mathrm{T}$ Bhatia. (eds). Handbook of language acquisition. San Diego: Academic Press.

SUZMAN, SM. 1992. The acquisition of Zulu. Unpublished PhD thesis, University of the Witwatersrand.

VAINIKKA, A. AND M YOUNG-SCHOLTEN. 1994. Direct access to X'-Theory: evidence from Korean and Turkish adults learning German. In Hoekstra, $T$ \& Schwartz, BD (eds) Language acquisition studies in generative grammar. Papers in Honour of Kenneth Wexler from 1991 GLOW Workshops. Philadelphia, PA: John Benjamins: 265-316.

VAINIKKA, A. AND M YOUNG-SCHOLTEN. 1996a. Gradual development of L2 phrase structure. Second Language Research, 12: 7-39.

VAINIKKA, A AND M YOUNG-SCHOLTEN. 1996b. The early stages in adult L2 syntax: Additional evidence from romance speakers. Second Language Research, 12 (12): 140-176.

WHITE, L. 1990/91. The verb-movement parameter in second language acquisition. Language Acquisition, 1: 337-60.

WHITE, L. 1991. Adverb placement in second language acquisition: Some effects of positive and negative evidence in the classroom. Second Language Research, 7: 133-60.

WHITE, L. 1992. Long and short verb movement in second language acquisition. Canadian Journal of Linguistics, 37: 273-86.

WHITE, L. 1996. Clitics in Child L2 French. In Clahsen, H. (ed). Generative perspectives on language acquisition. Amsterdam: John Benjamins: 335-368. 